\title{
Factors Influencing Project Success: A Qualitative Research
}

\author{
Nermina Durmic \\ International Burch University, Faculty of Engineering and Natural Sciences, Sarajevo, \\ Bosnia and Herzegovina
}

\begin{abstract}
This paper defines project success factors and aspects that are significant for successful project performance and outcomes, in the context of Information Technology (IT) projects. The list of total 38 factors is obtained through the qualitative content analysis of data collected via survey of 108 IT professionals, through one open-ended question. Detected factors are grouped into five categories: project team, project customer, project planning, project execution and project control. The results extend and support findings of the former quantitative study and the resulting project success model. They emphasize the significance of project team and project control activities for successful project outcomes.
\end{abstract}

Keywords - project success, project success factors, project performance, qualitative analysis, content analysis.

\section{Introduction}

To maintain a successful performance and reach their business goals, organizations today constantly need to adapt to changing market conditions and exponential technology and social changes.

Despite the efforts, wastes produced by failed or challenged projects in such environments are still high. PMI [1] reports that in 2017 the "underperforming" organizations, which are

DOI: $10.18421 /$ TEM93-24

https://doi.org/10.18421/TEM93-24

Corresponding author: Nermina Durmic, International Burch University, Sarajevo,

Bosnia and Herzegovina.

Email: nermina.durmic@ibu.edu.ba

Received: 08 June 2020.

Revised: 11 August 2020.

Accepted: 17 August 2020.

Published: 28 August 2020.

(cc)BY-NC-ND(C) 2020 Nermina Durmic; published by UIKTEN. This work is licensed under the Creative Commons Attribution-NonCommercial-NoDerivs 4.0 License.

The article is published with Open Access at www.temjournal.com organizations with less than $60 \%$ of projects being completed within time, budget and scope constraints, managed to complete around $38 \%$ of their project successfully. Another $38 \%$ was completed with challenges, and $24 \%$ was a complete failure. In 2018 and 2019 it was reported that organizations lost even up to $12 \%$ of their investment due to the poor project performance and failed projects [2], [3].

Reasons for project failures may be numerous. The PMI survey results from 2018 report that $41 \%$ of projects in observed organizations failed due to inadequate leadership and sponsor support. $52 \%$ of organizations experienced the scope creep, which even increased from $43 \%$ measured in 2013, and 5\% of underperforming organizations didn't have capabilities to deliver projects with expected values. In general, success of IT projects may depend on factors that come from five dimensions: (1) process success; (2) project outcome (product) success; (3) operation success; (4) business success; (5) strategic success and stakeholder satisfaction [4], [5].

With the aim of improving the project success statistics, Handzic \& Durmic [6] developed an empirically tested project success model which clarifies factors that are critical for successful project performance. The model connects people and process project aspects by combining the project management practices and concepts of knowledge capital, which is expected to be engaged more into all segments of the project development process for better project performance at all levels [2], [7]. The model is a result of a quantitative analysis of IT professionals' assessments of the quality of different project aspects and performance of project steps for their selected IT projects. While the model is statistically tested to be reliable, its qualitative confirmation is suggested as the next step.

As a response to this future research direction suggested by Handzic \& Durmic [6], the goal of this study is to test the proposed model and further clarify the significance of each model component through qualitative analysis of opinions and experiences of IT professionals, related to factors that made projects in their environments succeed or fail. 
The qualitative study is expected to investigate and answer the following: (1) Do people related success factors (project team and customer) influence the project success; (2) Do process related success factors (project planning, execution and control) influence the project success.

The paper is structured as follows: In the next section the proposed project success model is presented and research questions are developed. After that, the description of research methodology and data analysis method are provided. The study results and discussion of each research question are presented in the final sections, followed by concluding remarks and practical implications of the study.

\section{Project Success Model and Research Questions}

\subsection{Project Success Model Components}

The empirically tested project success model proposed by Handzic \& Durmic [6], presented in Figure 1., explains factors that make an impact on project performance and relationships between them. The model is composed of six components: project team and project customer that explain the people aspect of the model; project planning, project execution and project control components as phases in the process aspect; and project success component as the final goal of the project performance. The effects between these components are found to be both direct and indirect.

The model positions the process segment of project development to have the mediating role between project people and the final project outcome, indicating that higher involvement of both project team and customer in all three phases of project development process increases chances for a project to be successful. Furthermore, while project planning and control phases of the process aspect are positioned to have a clear direct effect on project success, the project execution phase makes an indirect impact through the project control phase. A direct link between project execution and project success is statistically not found to be significant. Considering how the proposed model defines the project execution phase, it becomes clear that enhanced project control and monitoring of architectural design and programming activities directly lead to enhanced rates of project success.

Among all factors, the proposed model reveals that project team and project control are the most significant ones, making the biggest influence on the project performance and the resulting outcome. They are two most complex factors in the model as well.

The project team is defined as a 5-dimensional element, being composed of team leadership, team members, team capabilities, team interests and team dynamics related sets of factors. The relationships between project team and project planning, execution and control are recognized as three most significant relationships in the model. Shortly, this element highlights the importance of having a good project manager and technical team leader in the project team, their capabilities and experience, team work, team commitment and participation in project activities, team composition, achievement of personal ambitions of team members, chances for promotion being given to team members, adding and removing people in project teams [6].

Project control, as the second most significant element of a project success, is a 3-dimensional element defined by issue management, project monitoring and quality assurance related sets of factors. Being the intermediate point between project

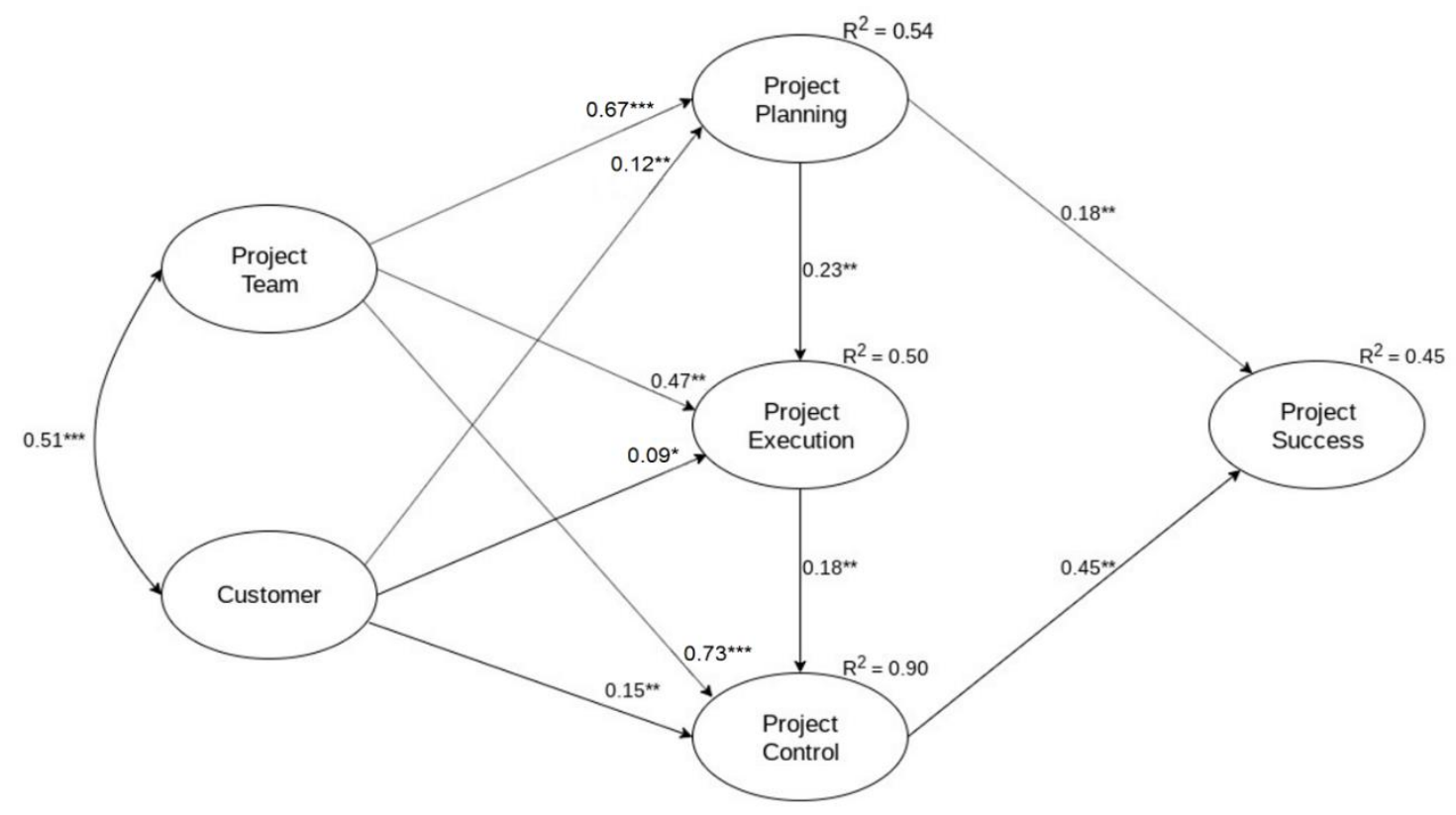

Figure 1. Project success model 
execution and project outcome, it focuses on software testing, verification and validation activities, finishing them on time, dealing with human error factor, technical difficulties, start-up difficulties, handling the overtime, time pressure and influence of the external parties and projects, application of knowledge and chosen software development methodologies, managing changes and risks, measuring the project outcomes and making decisions about the criteria for success of a given project [6].

The project planning element as a success factor in the proposed model is described by requirement analysis and specification activities, project size, technical and requirement complexity, project planning and scheduling, and understanding of project goals, mission and vision. Together with directly influencing the project success, the proposed model shows a direct link between project planning and project execution elements. In other words, the model suggests that the quality of performance of the planning process phase directly impacts the project execution process phase [6].

Finally, the customer element of the proposed model highlights the importance of the customer involvement in all phases of the project development process, their acceptance of the work done, resistance to adapt and change their requests when needed, and understanding of the issues they're dealing with in a given market.

\subsection{Research Questions}

Based on the constructs of the proposed project success model, five research questions (RQ) are defined for this study, as follows:

RQ1: Does project team influence the project success?

RQ2: Does project customer influence the project success?

RQ3: Does project planning as a project development phase influence the project success?

RQ4: Does project execution as a project development phase influence the project success?

RQ5: Does project control as a project development phase influence the project success?

\section{Research Methodology}

\subsection{Research Design}

Considering the complexity of the study, it was necessary to collect a wider sample of data from participants at different locations, thus survey with questionnaire as an instrument was recognized as the most suitable data collection method [8]. The questionnaire was composed of three sections: (1) section that collects demographic data about respondents; (2) section that captures information about complexity, success level and characteristics of an IT project a respondent selected to evaluate; (3) section with one open-ended question: "Which factors do you find to be critical for success or failure of the selected project?". The open-ended question design approach was selected to be the most suitable for data collection as the focus of this qualitative study was on gathering respondents' objective opinions about the topic without giving them any guidance.

\subsection{Study Participants}

The project success model proposed by Handzic \& Durmic [6] was built on data gathered from IT professionals based mostly in Europe and America. Considering that the goal of this study was to further test the proposed model within the given limits, the target survey respondents were members of IT project teams located in the same regions. 130 IT professionals were invited to take part in the research based on their experience, the role they have in project teams and the type of projects they had a chance to work on, and 108 of them accepted the invitation. Data was collected by sending the survey link directly to selected IT professionals, with explanation of the purpose of the study. Collected data were reviewed and after the data cleaning process 4 responses were found to be irrelevant for the study and removed from the qualitative data set. According to Fridlund \& Hildingh [9], the sample size of 104 responses is found to be more than sufficient for performing the qualitative analysis.

$54 \%$ of respondents were based in Europe, and $46 \%$ were based in the American region, $87 \%$ male and $13 \%$ female. $62 \%$ were technical stuff holding different roles in development teams, and $38 \%$ were technical and non-technical managers. The goal was to involve both technical and business aspects of the IT project development process, thus it was necessary to involve the non-technical roles in the research as well. The majority of respondents were aged between 31 and 50, 66\% exactly. $19 \%$ belong to the age group of 22 to 30 , and the remaining $15 \%$ were between 51 and 61 years old. The respondents had 16 to 20 years of experience on average. $64 \%$ of them had a Bachelor level of education, $33 \%$ held Masters and 3\% held $\mathrm{PhD}$ degrees.

\subsection{Data Analysis Method}

Content analysis was chosen as the most suitable method for analyzing data collected in the form of a text. It enables a systematic and objective process of making replicable and valid results from any type of 
written data, where results are linked to contexts of their use [10], [11]. The process for performing the content analysis was adopted from Bengtsson [12], who finds that majority of researchers perform the content analysis through four major stages: (1) the decontextualisation; (2) the reconstextualisation; (3) the categorization and (4) the compilation.

In the first step (decontextualisation) the author got familiar with the content to be analyzed and the coding process was performed manually. Given that research questions in this study were designed based on results of the former quantitative study, the purpose of this study was found to be explanatory based on deductive reasoning. In deductive analysis approach, questions and principles are being tested by detecting predefined subjects in data [13]. Thus, the coding list that was used in the coding process in this study was defined before data analysis started. The list was defined based on the list of success factors established through the factor analysis in the former quantitative study. The coding list was composed of 65 factors.

As part of the second step (reconstextualisation) the author read the content again to mark the text that covers aspects of the research. The unimportant information in the text that doesn't correspond to the study topic and research questions and that was not coded was discarded.

In the third step (categorization), codes were classified into subcategories, and subcategories were grouped into categories. Definition of categories was

Table 1. Content analysis coding results guided by the study research questions and factor grouping in the former quantitative study.

Finally, in the fourth step (compilation) the analysis results were given a meaning and conclusions were written up. Both manifest and latent analysis levels were used to analyze the final results and describe their indications. Survey responses that were shorter, clear and straightforward were suitable for the manifest analysis, while all other responses had to be analyzed at the latent level to be interpreted [12].

\section{Results}

\subsection{Coding Results}

The results of the coding process in the performed content analysis are presented in Table 1.

Out of predefined 65 codes that represent project success factors, 36 were detected in the analyzed content, and 4 new codes were added during the coding process. Identified codes are classified into 11 subcategories, and subcategories are classified into 5 categories: project team, project customer, project planning, project execution, project control. The classification was established to be in accordance with factor grouping in the former quantitative analysis. While project team and project control are found to be more complex and composed of 5 and 3 subcategories respectively, project customer, project planning and project execution categories remained equivalent to their subcategories.

\begin{tabular}{|c|c|c|c|c|c|}
\hline Category & Subcategory & Code & $\begin{array}{l}\text { Freq. per } \\
\text { code }\end{array}$ & $\begin{array}{c}\text { Freq. per } \\
\text { subcategory }\end{array}$ & $\begin{array}{l}\text { Freq. per } \\
\text { category }\end{array}$ \\
\hline \multirow{11}{*}{ Project Team } & Project Leader & Project Manager & 23 & 23 & \multirow{11}{*}{99} \\
\hline & \multirow{4}{*}{ Team Members } & Team work & 35 & \multirow{4}{*}{40} & \\
\hline & & Personal issues (ego) & 3 & & \\
\hline & & Working environment & 1 & & \\
\hline & & Patience & 1 & & \\
\hline & Team Capabilities & Knowledge and technical skills & 18 & 18 & \\
\hline & \multirow{3}{*}{ Team Interests } & Rewards & 4 & \multirow{3}{*}{6} & \\
\hline & & Recognition & 1 & & \\
\hline & & Motivation & 1 & & \\
\hline & \multirow{2}{*}{ Team Dynamics } & People come and go & 7 & \multirow{2}{*}{12} & \\
\hline & & Offshore team members & 5 & & \\
\hline \multirow{3}{*}{$\begin{array}{l}\text { Project } \\
\text { Customer }\end{array}$} & \multirow{3}{*}{ Project Customer } & Customer involvement & 14 & \multirow{3}{*}{16} & \multirow{3}{*}{16} \\
\hline & & Customer acceptance & 1 & & \\
\hline & & Third party vendors's support & 1 & & \\
\hline \multirow{2}{*}{\begin{tabular}{|l|} 
Project \\
Planning
\end{tabular}} & \multirow{2}{*}{ Project Planning } & Requirements specification & 19 & \multirow{2}{*}{58} & \multirow{2}{*}{58} \\
\hline & & Scheduling and estimations & 15 & & \\
\hline
\end{tabular}




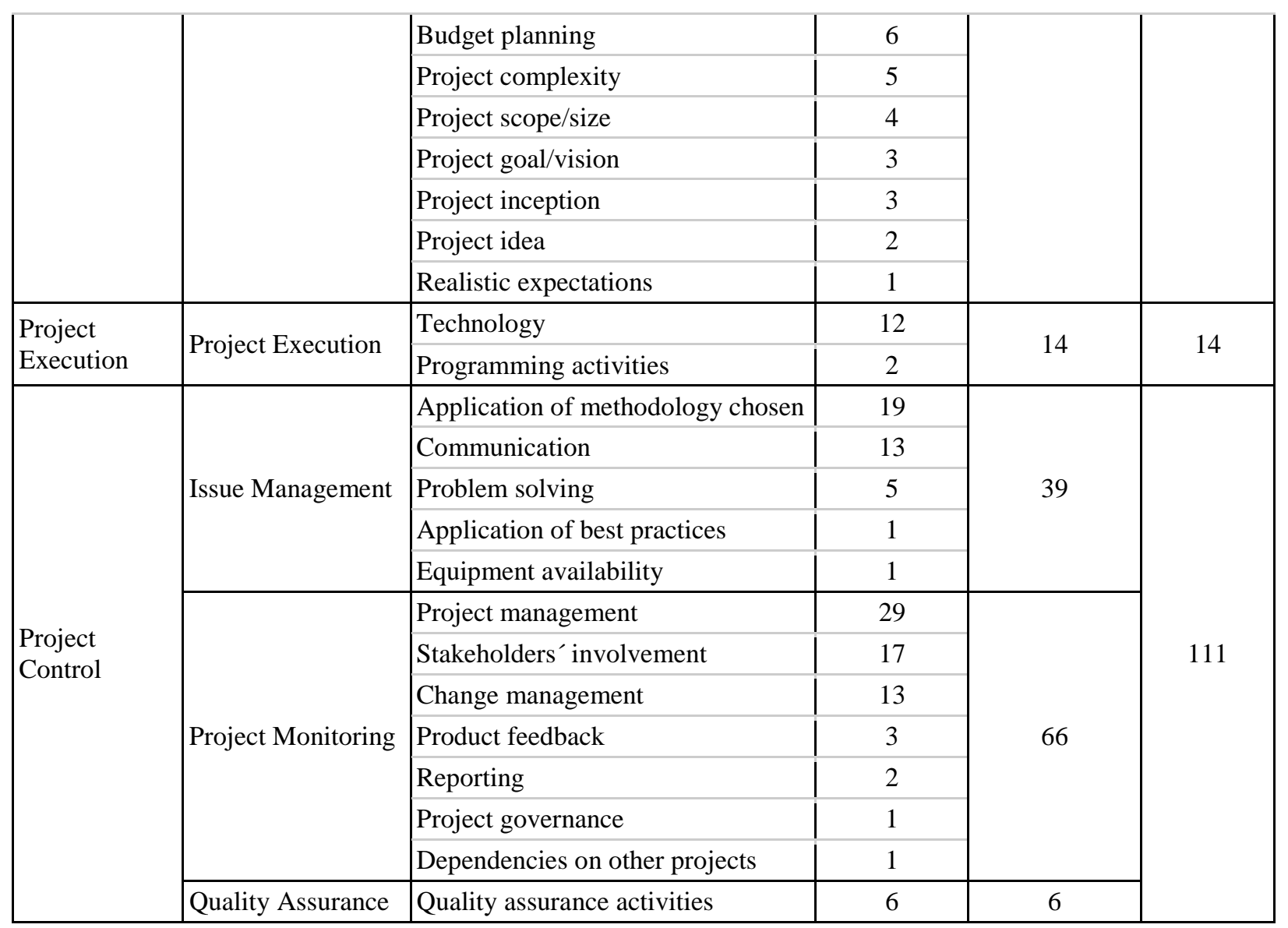

The frequency of appearances of individual codes in the analyzed content varies from minimum 1 to maximum 35. The summarized code appearance count goes from 6 to 66 in subcategories, and from 14 to 111 in categories.

With respect to the maximum number of code appearances in categories, the author established a significance scale to be used in discussion of research questions. The scale is presented in Table 2 . According to the scale, it is found that two success factor categories are highly significant (project team and project control), one is medium significant (project planning), and two are low significant for the success of a project (project execution and project customer). Figure 2. shows the distribution of code appearances among code categories.

Table 2. Significance scale for code categories

\begin{tabular}{|c|c|}
\hline Significance level & Scale \\
\hline Low $(*)$ & 1 to 37 appearances \\
\hline Medium $(* *)$ & 38 to 74 appearances \\
\hline High $(* * *)$ & 75 to 111 appearances \\
\hline
\end{tabular}

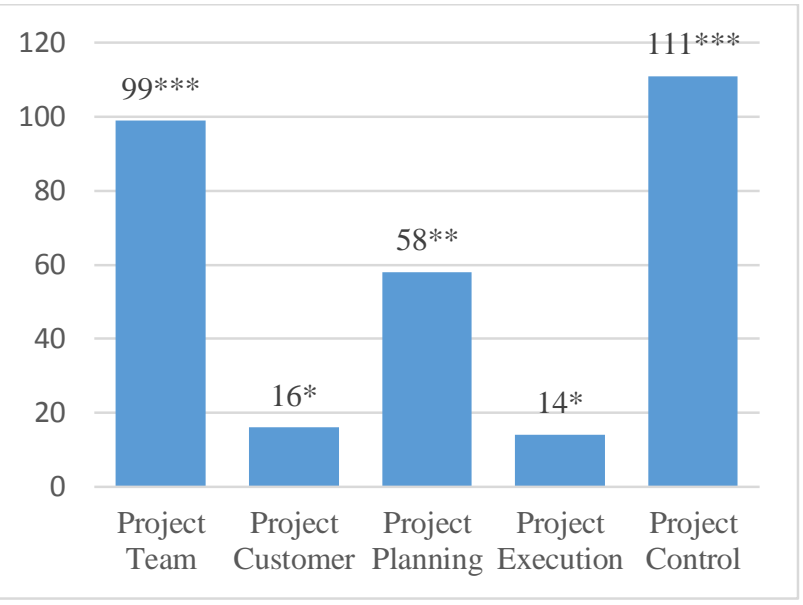

Figure 2. Distribution of code appearances among categories

\subsection{Discussion}

The qualitative content analysis was performed in this study to analyze opinions of IT professionals about factors that make their projects successful. The analysis results answered all research questions positively, with different levels of significance. Each research question is discussed in detail in the following sections. 


\section{RQ1: Does project team influence the project success?}

Project team is found to be one of two factor categories that make the highest impact on success or failure of the project outcome according to the study results.

The experiences of survey respondents show that among all tested factors, they see the teamwork as the most important initiator of a successful project performance. Teamwork factor has the highest code loadings in the study. Its significance for a project success was also discussed in the earlier studies, like Crawford \& Turner [14] and Henderson [15].

For a project that failed in all aspects - it was completed out of defined scope, it was over budget and estimated time for completion, a software architect with 15 years of experience says: „An interesting case of lots of good people who didn't know how to work together. Also, there was no experience from the management on how to manage a big engineering project. "

The positive impact of the teamwork factor on project performance can also be explained by a comment of a junior software developer, given for a project that was completed successfully. It says: "Upper management furnished enough money. Middle and Project management was nearly nonexistent, and cost the project at least 6 months. The project would have failed except for the quality and commitment of the team members and the team work."

Together with the teamwork, project manager and knowledge and technical skills of the team are two factors that guide the success of a project team category according to the study results. This conclusion was expected considering that the project manager is a project team member who is shared among all process phases, segments and aspects of a project. In addition, knowledge and capabilities of a project manager and the entire team are crucial for ensuring the quality of the final project outcome and project activities to be delivered with no time wastes. The confirmation for these findings can also be found in Camilleri [16] and Verzuh [17].

The following comment of a test engineer with 17 years of experience advocates this finding: "The project was successfully delivered and even won an award. A good working environment, where the Project Manager helped the team thrive, was the key to success."

A consulting director with 20 years of experience comments on a successfully completed high complexity project he was a part of: „Project failed largely due to "internal politics" as it changed hands from "R\&D" to "production". Further, Project Manager and Lead were in conflict largely due to egos. Finally, better leadership and management lead to a successful outcome despite initial hiccups."

Team dynamics is another important factor that defines the project team category. According to study participants, people being added to the project is found to be even more challenging than losing project team members. Time that needs to be spent on educating new team members by the team while the project execution is ongoing is one of the main reasons. In addition, team members being geographically distributed is often a roadblock to achieving the project success according to the study results. This finding is also supported by Morisio et al. [18] and Kappelman et al. [19].

A systems engineer with 5 years of experience whose high complexity project was challenged and ended to be partially successful shares that: "Recent organizational changes and shuffling of resources have been an obstacle (at the beginning) due to an adjustment to new roles. However, as of late, they have had a positive impact on work, streamlining the reporting process."

A similar observation comes from a technical process manager with 10 years of experience who worked on a project with medium complexity: "Customer changed scope a couple of times during development, and was willing to pay for the additional personnel needed to achieve it without compromising on the deadline. Quickly expanding the size of the team and managing space and equipment logistics was challenging."

Occasional rewards for the project accomplishments usually make the project success a personal ambition for team members. For this reason study participants find that rewarding project team members is also a factor that makes a positive impact on project success. This observation is also supported by Zouaghi \& Laghouag [20]. However, while the former quantitative analysis and the proposed model rank the motivation, rewards and team recognition very high on the project success factor scale, this study finds them important, but not as significant as other project team related factors.

Findings in this research question confirm the significance of the project team component for the project success indicated by the proposed project success model. The most important project success factors in this study are also listed as the most important success factors in the project team component in the former quantitative study and the proposed model.

On the other hand, this study doesn't find support for a technical team lead to be a success factor for the project team component, which is recognized to play an important role in project team according to the former quantitative study results. Furthermore, this study also doesn't find support for factors like 
respect for team hierarchy, team building, team composition, education and training provision, company interest being aligned with personal interests, which rank as fairly high factors of the project team component in the proposed model. This study doesn't recognize these factors as drivers of a project success.

\section{RQ2: Does project customer influence the project success?}

The analysis results indicate that project customers have a significant role in the project success achievement, but with lower significance compared to other factor categories in this study. This finding is in line with findings in the quantitative study and the proposed model.

While significance of the project customer is described with several factors in the proposed model, the qualitative analysis finds that the only major factor in the project customer category critical for project success is customer involvement factor, with no variations. All study participants who brought up this factor as a significant one agree that right guidance of customers throughout the project development process will ensure the availability of the necessary customer feedback for the work done. This leads back to the importance of the project manager role which is a connection point between customer and project with all of its components.

A technical process manager with 28 years of experience comments on the medium complexity project he worked on: „The success of this project was due to the commitment of the client, meeting all requirements, and solving problems quickly found. Another positive was the high level technical team."

Customer involvement is also discussed as an important factor of project success in previous studies, like Nasir \& Sahibuddin [21] and Egorova et al. [22].

\section{RQ3: Does project planning as a project development phase influence the project success?}

Code loadings for project success factors that define the project planning category as a project development process phase indicate that project planning influences the success of the final project outcome, with medium significance compared to other project success factors in this study.

There are two factors in focus in this category that play a critical role for successfully performed planning activities: requirements specification and scheduling and estimation.

The study results suggest that it's advisable to spend a good amount of time on analysis and definition of project requirements to avoid any possible ambiguities that may arise once the project execution phase starts. A proper documentation of defined requirements is also crucial. Furthermore, good and detailed scheduling that aligns planned requirements with people resources available is an inevitable component of the project planning phase. The study participants say that providing a good estimation of the work that needs to be done is usually very challenging, especially when requirements are changing during the project development. Nevertheless, according to the study results the estimation factor stands for one of critical planning activities as it dictates deadlines and promises made to customers. Support for these conclusions can also be found in Camilleri [16] and Padgett [23].

At least $20 \%$ of the study participants find incomplete requirements to be the main cause of their projects being challenged, or complete project failures. The reason behind is usually twofold. If the project team is proactive the unknowns in the project requirements are discovered in the project execution phase, and additional resources are spent for further clarification of requirements which results in team demotivation, as well as time and budget loss. In the other case scenario, the project team may be more static or less experienced, and may accept the requirements as they are which then leads to wrong or incomplete implementation of requested product features. In any case, the chances for a successful project completion are very low.

A director of development with 16 years of experience whose project was completed with challenges says: „The main problems were: (1) unclear requirements; (2) refusal of the product management team to define a scope that fits the available capacity; (3) animosity between sub-teams (server development, client development, QC); (4) lack of clear direction from the business: goal / vision / high level requirements. In the end, a smaller than desired product was delivered on time, but only over objections and recriminations from the product management team."

A statement that came from a medior software engineer who commented on his failed project summarizes observations of many of the study participants in the aspect of project requirements. It says: „This project was an example of the cliche: „You start programming, I'll go find out what they want." "'

Budget planning, as well as the project size and complexity are also defined as project planning factors that have an impact on project success according to the study results. This is in line with findings in Zwikael \& Smyrk [24].

The results also indicate that the project idea itself and a good start of the project (project inception), 
together with realistic expectations, may contribute to successful performance of a project. The support for these project success factors can be found in Hirshfield \& Lee [25].

In a comment for his high complexity project that ended as a partial success, a software engineer with 10 years of experience says: „Vision of management about the project was completely disconnected from the reality of the customers. The project was not well received."

Findings related to this research question give support for every success factor that describes the project planning component in the proposed model. In other words, there is no success factor listed as significant under the project team component in the former quantitative study that was not found to be a potential project success contributor by this study.

\section{RQ4: Does project execution as a project development phase influence the project success?}

The study results answer this question positively, however the project execution phase is found to have the least impact on the project success, among all other factors and aspects tested in this study. Considering that the proposed model and the former quantitative study results find the execution phase to have only the indirect impact on the project success, and not a direct one, it can be concluded that both studies agree about the level of significance of the project execution phase for project success.

The support for architectural decisions and design as tested factors that belong to the project execution phase in the proposed model is not found in this study at all. Only a slight support is found for programming activities to be a success factor that belongs to the project execution phase.

On the other hand, while technology and its application was not recognized as a significant factor of the project execution phase in the proposed model and the quantitative study, this study recognizes it as a factor that is the most responsible for success of a project execution phase, in the range it is defined by the study results. Study participants find that technology challenges may slow down the execution phase in case of more complex projects. On the other hand, well selected technology may ease the project execution phase which then contributes to a more successful project performance.

After completing his high complexity project successfully, a software engineer with 10 years of experience finds that: "Time factor and technology make the project succeed in the hands of the knowledgeable team members."

Support for findings related to this research question can be found in Zwikael \& Smyrk [24], Emmanouilidis et al. [26].

\section{RQ5: Does project control as a project development phase influence the project \\ success?}

According to study results the project control category is the most complex category with highest code loadings of its factors. Together with the project team, the project control phase is found to be the most significant influencer of the project success.

The proposed model indicates the same conclusion, meaning that results in this study support findings in the former quantitative study. An interesting remark is that while results of the quantitative analysis find the project team to be the most significant project success component followed by the project control, this study results find the project control to have a slightly higher impact on the project success compared to the project team.

The results indicate that project control component representing a phase of a project development process focuses on close project monitoring first, followed by issue management with the aim of removing any impediments to success that may arise, and completes the process with quality assurance activities that ensure functional quality of the resulting product that will be delivered to customers.

Although quality assurance and code testing was recognized as a significant success factor, the expectation was that it has higher factor loadings, which was the case in the former quantitative study.

Based on the views of study participants, good management of project activities by project manager and other team members, together with regular monitoring of the process outcomes by stakeholders is crucial for ensuring a good project monitoring. In addition, the way changes are being managed, communicated and implemented affects the project performance pace and the final project outcome significantly.

In a comment for his partially successful project, a junior software engineer says: "Requirement was rapidly changing, the most difficult task for us was to keep up with the change without slowing down the development process."

Even if a software development methodology itself can't ensure a successful project outcome, the study participants state that developing a software without following any methodology may be a cause of big problems throughout the development process and leads to project failures. Proper application of a chosen methodology contributes to issue management and faster execution of defined activities.

In this aspect, a project manager with 12 years of experience shares: "The change to agile methodologies was appropriate and part of our success!" 
A software developer with 23 years of experience shares a similar statement in a comment about his successfully completed project: "We experienced again that each step of the project life cycle should be handled accordingly to process, procedures and standards. People can successfully overcome every problem if they are motivated."

Experiences of study participants also show that good communication makes the problem solving easy and efficient. The lack of communication also challenges the project performance in a big range.

"If you want to complete projects successfully, you must have patience, good communication skills and more tolerance", shares a project manager with 23 years of experience in a comment about his successfully completed project.

Support for findings related to this research question can also be found in the previous studies, like Asemi \& Jazi [27] and Kanter \& Walsh [28].

The overall importance of project control and monitoring activities can be summarized by the two following comments given by test manager and product manager respectively, both with 20 years of experience, who worked on two different projects that were completed with challenges:

(1) "Like most challenged projects, insufficient consideration was given to requirements, design and coding. Test phases were used to construct and mop up issues and essentially became another build phase rather than an independent validation and verification exercise. Senior management moved leadership from one phase to the next throughout the lifecycle and therefore it became impossible to direct attention to any of the phases."

(2) "This was a typical IT deployment project, not technically challenging but with many stakeholders.

The biggest challenge was meeting all of the expectations of the many stakeholders, and bringing through the final 10-15\% of the coding and deployment phase when team members started losing their focus and looking towards their next project."

All highly significant project control factors in the proposed model are confirmed by results in this study. Factors that didn't find their confirmation in this study are: handling the overtime and time pressure, budget-cost estimations, risk management, measurement systems, authority delegation. These factors are not recognized as critical ones for the project success.

\section{Conclusion}

The purpose of this study was to test the project success model proposed by Handzic \& Durmic [6] and to further clarify the importance of involved factors for project success. This is accomplished by performing the qualitative analysis of data collected in IT project environments. The results provide support for the proposed model, with minor changes. They indicate that project team and project control components have the highest influence on the project success, project planning has a medium impact, while project customer and project execution components have lower impact on the project success. Each of the components is described with project success factors detected to be critical for the component performance and the final success of a project. Although all factors suggested by Handzic \& Durmic [6] have been included in the coding list in the qualitative analysis, this study concludes that $60 \%$ of these factors are critical for project success.

The contribution of this study is two-fold: (1) it updates the project management literature with the list of project success factors tested on recent IT projects; (2) it provides valuable guidelines to project based organizations about key points to pay attention to when establishing project environments and managing project processes. The study implies that for successful outcomes organizations should first invest in people and their knowledge to establish teams of people who know how to work together and who are capable of facing project challenges. An authorized project manager who helps the team thrive, who ensures clear requirement definition before programming stats, and who involves customers and stakeholders from the beginning until the end of project development is inevitable for project success. Close monitoring of project activities to prevent the risk of failure is highly advised.

These implications best correspond to projects in European and American organizations, as the study results are based on data collected from IT professionals based in these regions. This is the main limitation of the study.

Considering that different project development methodologies organize project development processes differently, a suggestion for future research direction is to test whether the project success model and list of critical project success factors change depending on project development methodology being practiced on a given project. In addition, it is suggested to qualitatively analyze the significance of relationships between project development process steps, which was not in focus in this study. 


\section{References}

[1]. PMI (Project Management Institute). (2017). Success Rates Rise - Transforming the High Cost of Low Performance. Newtown Square, PA: Pulse of the Profession®. Retrieved from: https://www.pmi.org//media/pmi/documents/public/pdf/learning/thoughtleadership/pulse/pulse-of-the-profession-2017.pdf [accessed: 10 January 2020].

[2]. Langley, M. A. (2018). Success in Disruptive Times: Expanding the Value Delivery Landscape to Address the High Cost of Low Performance. Project Management Institute, Newtown, USA.

[3]. PMI (Project Management Institute). (2019). The Future of Work: Leading the Way With PMTQ. Retrieved from: https://www.pmi.org//media/pmi/documents/public/pdf/learning/thoughtleadership/pulse/pulse-of-the-profession2019.pdf?sc_lang_temp $=$ en [accessed: 15 January 2020].

[4]. Bannerman, P. L. (2008, July). Defining project success: a multilevel framework. In Proceedings of the Project Management Institute Research Conference (pp. 1-14).

[5]. El-Masri, M. (2009). A model of IS project success. In Proceedings of Administrative Association of Canada Conference (ASAC) (Vol. 30, No. 4).

[6]. Handzic, M., \& Durmic, N. (2015, September). Realizing value from knowledge assets: Empirical study in project environment. In Proceedings of the 16th European Conference on Knowledge Management, Udine.

[7]. Yeong, A., \& Lim, T. T. (2010). Integrating knowledge management with project management for project success. Journal of Project, Program \& Portfolio Management, 1(2), 8-19.

[8]. Kabir, S. M. S. (2016). Methods of data collection. Book Zone Publication.

[9]. Fridlund, B., \& Hildingh, C. (2000). Health and qualitative analysis methods. Qualitative research methods in the service of health, 13-25.

[10]. Giannantonio, C. M. (2010). Book Review: Krippendorff, K.(2004). Content Analysis: An Introduction to Its Methodology . Thousand Oaks, CA: Sage. Organizational Research Methods, 13(2), 392-394.

[11]. Downe-Wamboldt, B. (1992). Content analysis: method, applications, and issues. Health care for women international, 13(3), 313-321.

[12]. Bengtsson, M. (2016). How to plan and perform a qualitative study using content analysis. NursingPlus Open, 2, 8-14.

[13]. Priest, H. M. (2006). Essentials of nursing research: Methods, appraisal, and utilization. Nurse Researcher, 13(4), 91-93.
[14]. Crawford, L. W., \& Turner, J. R. (2007). Developing the project management competence of individuals. Gower handbook of project management, 4, 678-694.

[15]. Henderson, P. (2006). Why large it projects fail. ACM Trans. Program. Lang. Syst, 15(5), 795825.

[16]. Camilleri, E. (2012). Project success: critical factors and behaviours. Gower Publishing, Ltd.

[17]. Verzuh, E. (2015). The fast forward MBA in project management. John Wiley \& Sons.

[18]. Morisio, M., Egorova, E., \& Torchiano, M. (2007). Why software projects fail? Empirical evidence and relevant metrics. Proc. of Mensura, 299-308.

[19]. Kappelman, L. A., McKeeman, R., \& Zhang, L. (2006). Early warning signs of IT project failure: The dominant dozen. Information systems management, 23(4), 31-36.

[20]. Zouaghi, I., \& Laghouag, A. (2012). Empirical study of key success factors in IS projects. Cahier De Recherche No 2011-06, E5,Version 1.

[21]. Nasir, M. H. N., \& Sahibuddin, S. (2011). Critical success factors for software projects: A comparative study. Scientific research and essays, 6(10), 21742186.

[22]. Egorova, E., Torchiano, M., Morisio, M., Wohlin, C., Aurum, A., \& Svensson, R. B. (2009, August). Stakeholders' perception of success: An empirical investigation. In 2009 35th Euromicro Conference on Software Engineering and Advanced Applications (pp. 210-216). IEEE.

[23]. Padgett, C. M. (2009). The Project Success Method: A Proven Approach for Achieving Superior Project Performance in as Little as 5 Days. John Wiley \& Sons.

[24]. Zwikael, O., \& Smyrk, J. (2011). Project management for the creation of organisational value. London: Springer.

[25]. Hirshfield, M., \& Lee, P. D. (2006). Critical success factors for healthcare software implementations. Health Care Manager, 25(4), 310314.

[26]. Emmanouilidis, C., Koronios, A., Mathew, J., \& Kiritsis, D. (Eds.). (2010). Engineering Asset Lifecycle Management. In Proceedings of the 4th World Congress on Engineering Asset Management (WCEAM 2009), 28-30 September 2009. Springer.

[27]. Asemi, A., \& Jazi, M. D. (2010). A comparative study of critical success factors (CSFs) in implementation of ERP in developed and developing countries. International Journal of Advancements in Computing Technology, 2(5), 99-110.

[28]. Kanter, J., \& Walsh, J. J. (2004). Toward more successful project management. Information systems management, 21(2), 16-21. 